Mens

Revue d'histoire intellectuelle et culturelle

mens

Aurélie Lacassagne. Perspectives créoles sur la culture et

l’identité franco-ontariennes : essai sur une prise de parole, Sudlbury, Éditions Prise de parole, 2017, 199 p.

\title{
Nicolas Nicaise
}

Volume 19, numéro 1-2, automne 2018, printemps 2019

URI : https://id.erudit.org/iderudit/1070080ar

DOI : https://doi.org/10.7202/1070080ar

Aller au sommaire du numéro

Éditeur(s)

Centre de recherche en civilisation canadienne-française

ISSN

1492-8647 (imprimé)

1927-9299 (numérique)

Découvrir la revue

Citer ce compte rendu

Nicaise, N. (2018). Compte rendu de [Aurélie Lacassagne. Perspectives créoles sur la culture et l'identité franco-ontariennes : essai sur une prise de parole,

Sudbury, Éditions Prise de parole, 2017, 199 p.] Mens, 19(1-2), 230-233.

https://doi.org/10.7202/1070080ar d'utilisation que vous pouvez consulter en ligne.

https://apropos.erudit.org/fr/usagers/politique-dutilisation/ 


\section{Aurélie Lacassagne. Perspectives créoles sur la culture et l'identité franco-ontariennes: essai sur une prise de parole, Sudbury, Éditions Prise de parole, 2017, 199 p.}

Cet essai sur une prise de parole franco-ontarienne est, comme le genre y invite, prise de parole, de position dans et sur un milieu culturel, dans lequel elle s'enracine, de manière rhizomique, comme l'écrira l'auteure. C'est la grande connaissance du milieu, de ses acteurs qui donne sa force au livre, sa cohérence, son style, en plus d'une réflexion théorique de qualité et toujours bien amenée. L'exercice est d'autant plus difficile qu'il doit tenir compte de son contexte et pourtant, c'est paradoxalement par cet ancrage que le propos porte, bien au-delà, et gagne à être entendu, discuté, surtout en ces temps-ci. Le texte est politique, réflexif, mais part du vécu de l'auteure, de son parcours. Celle-ci accompagne le lecteur à travers un texte fragmenté. Après s'être interrogée sur les différents concepts et théories, connus de celles et ceux qui s'intéressent aux pratiques culturelles en milieu minoritaire ou plus largement aux cultural studies, elle file la métaphore de la créolisation des cultures et des identités. En référence à Édouard Glissant, la notion est centrale dans la réflexion et traverse tout l'ouvrage.

Comme nous l'avons mentionné, le texte s'organise à partir du parcours personnel de l'auteure, de réflexions théoriques, mais bascule ensuite dans une forme de dialectique entre les conditions matérielles, historiques et la création d'un nouvel espace. Ce basculement opère en mettant en valeur les textes des plus jeunes, au regard du travail de leurs aînés en poésie comme au théâtre. On passe ainsi des premières lectures et découvertes, Robert Dickson et Patrice Desbiens, à celles de Jean Marc Dalpé ou encore de Daniel Aubin. Le ton est vif, parfois irrévérencieux et branché comme les textes que l'on (re) découvre sur le politique. Ce parcours permet au lecteur de profiter également des textes, mais aussi des analyses qui retracent l'évolution esthétique en lien avec les questions d'identité, de langue, la place accordée à l'Autre, les représentations des lieux 
et des espaces du paysage culturel franco-ontarien avec leurs particularités, mais aussi leurs rapports avec d'autres espaces franco-américains. On retrouve ici des questionnements connus, mais ils sont mis en vis-à-vis, dans un essai qui, à bien des égards, ressemble à un recueil de textes, avec des passages politiques qui jouent de deux tonalités. Aux aspects plus critiques, lorsqu'il s'agit de l'influence du rapport Durham (1839), des politiques culturelles qui mettent en concurrence les communautés (anglophones, francophones, autochtones ou "ethno-culturelles», par exemple), s'ajoutent des accents plus revendicateurs, un engagement sur les plans individuel et collectif. C'est le cas lorsqu'il est question de définir la communauté comme culturelle, avant d'être politique, ethnique ou linguistique (p. 179) ou quand l'essayiste envisage le développement de la communauté au-delà de la question des droits linguistiques (p. 182), par exemple.

Mais c'est également un texte qui avance et prône un discours dans lequel le processus de créolisation des identités et des cultures s'oppose à une forme de dualisme ancré dans un habitus de la communauté franco-ontarienne. C'est là sans doute que se révèle la portée subversive de l'essai et des textes plus récents. L'auteure, à l'aide de la notion de créolisation des identités, va à l'encontre d'une conception plus restreinte de celles-ci; une vision que peut représenter, selon l'auteure, celle de métissage (plus «biologisante», p. 49). Plus fondamentale, l'opposition entre créolisation et dualisme apparaît comme décisive. Dans la foulée de l'organisation du festival Upfest (2015), l'auteure remarque que "[d]» aucuns se sont plaints que des jeunes francophones mettent autant d'énergie et de temps pour organiser un événement où l'anglais prédominait (même si un bon tiers des artistes étaient francophones) » et dresse un parallèle avec la non-reconnaissance de ce nouveau discours émergeant depuis quinze ans (p. 174). La remise en question de cette dualité chez Aubin (p. 165) passe par une forme de radicalité:

je n'accepte pas

la dualité 
que mes parents

m'ont inculquée

good and evil

french and english (Néologirouettes, p. 43)

Le refus du dualisme s'accompagne pour l'essayiste d'une critique, voire d'un rejet d'une forme de "schizophrénie linguistique" (p. 57-58). À travers tout l'essai, il y a en effet une volonté de mettre l'accent sur une transformation chronologique et discursive. En schématisant, on passe de la reconnaissance d'une parole, du balbutiement institutionnel à l'affirmation de conditions d'existence culturelles et identitaires thématisées dans un lexique particulier, celui du cri, du creux, de l'amphibien, de l'«in-between» (p. 136), du fait "d'être pogné entre" (p. 146), à un renversement axiologique du vide vers le plein, du négatif au positif. Il s'agit d'un indice qui marque l'émergence d'un discours, le moment d'un engagement et d'une projection dans l'avenir et dans un idéal. En filiation avec Shengor et dans la foulée d'un discours francodoxe, elle écrit: «[...] la francophonie comme "idéal" et non comme idéologie" [...] parce qu'il s'agit bien d'une culture commune, d'un idéal commun, d'un respect commun entre les peuples et non d'une question linguistique» (p. 58).

C'est d'ailleurs là que s'arrête le schéma esquissé parce qu'une partie du lexique employé demeure très actuel et s'inscrit dans une certaine continuité avec le discours des devanciers. Quant à la question linguistique, elle me semble, elle aussi, demeurer importante, ne fût-ce que pour maintenir le caractère particulier de la prise de parole poétique, auquel l'essayiste accorde d'ailleurs une grande importance, par rapport à la communauté culturelle au sens large dans laquelle les phénomènes de représentations sociolinguistiques demeurent des facteurs puissants de détermination.

La projection dans l'avenir, qui est un appel à l'agir maintenant auquel participe véritablement l'essai, appelle cette distinction sur la fonction et la spécificité du discours littéraire: "Ce qui 
forme l'identité collective, ce sont les divagations, les pérégrinations des poètes dans cet espace d'infinis où tout devient possible, où l'on parvient à sortir de l'exiguïté (du trou, du manque institutionnel, des trous de langue) pour rentrer dans le futur» (p. 37). Ce passage sur l'identité peut également s'appliquer à la culture, à la littérature. Les figures du poète, de l'écrivain comme du dramaturge sont au cour du processus, tout comme les institutions de la vie culturelle d'ailleurs. Mais pas n'importe laquelle, on l'aura compris: celle d'une culture fondée sur l'identité-relation, sur le rhizome (et non la racine unique), une culture cosmopolite, appelée des vœux de l'auteure: «Il s'agira donc de trouver l'Autre qui est en nous, celui qui fait Relation. Il faudra faire imploser les dichotomies centre-périphérie; dominant-dominé; colonisateur-colonisé. Alors seulement, un monde, que j'appelle cosmopolite, pourra voir le jour» (p. 43). Reste à concilier, dans ce programme, la reconnaissance de l'Autre en nous et cette culture commune. Selon les interprétations du sens donné au terme "cosmopolite», un tel rapprochement pourrait aussi bien mener à une forme d'aporie. À chaque lecteur d'en juger.

Stagiaire postdoctoral à l'Institut d'études acadiennes Université de Moncton

\section{Julien Goyette. Temps et culture: Fernand Dumont et la philosophie de l'histoire, Québec, Presses de l'Université Laval, 2017, 251 p.}

Dans la mer des travaux sur Fernand Dumont, le livre de Julien Goyette apparait comme un roc: il délimite un territoire et s'impose comme un repère incontournable. L'allégorie nautique est en fait bien invitante pour parler de ce livre, puisque c'est en véritable cartographe conceptuel, un œil sur ses cartes, l'autre sur les étoiles et la main sur son sextant, que Goyette nous fait cheminer dans l'œuvre touffue et hétéroclite de Dumont. Mais cette traversée ambitieuse se fait au prix d'un horizon, celui de la terre ferme, et confronte volontiers le lecteur (-historien) qui n'a pas le pied marin (théorique). 